\title{
Video Elicitation Interviews: A Qualitative Research Method for Investigating Physician-Patient Interactions
}

\author{
Stephen G. Henry, MD ${ }^{1,2}$ \\ Michael D. Fetters, MD, MPH, $M A^{3}$ \\ 'VA Ann Arbor Healthcare System, Ann \\ Arbor, Michigan \\ ${ }^{2}$ Department of Internal Medicine, Uni- \\ versity of Michigan Medical School, Ann \\ Arbor, Michigan \\ ${ }^{3}$ Department of Family Medicine, Univer- \\ sity of Michigan, Ann Arbor, Michigan
}

Conflicts of interest: authors report none.

\section{CORRESPONDING AUTHOR}

Stephen G. Henry, MD Robert Wood Johnson Foundation Clinical Scholars Program 6312 Medical Science Bldg 1

University of Michigan 1150 W Medical Center Dr Ann Arbor, MI 48109 henrstep@umich.edu

\begin{abstract}
We describe the concept and method of video elicitation interviews and provide practical guidance for primary care researchers who want to use this qualitative method to investigate physician-patient interactions. During video elicitation interviews, researchers interview patients or physicians about a recent clinical interaction using a video recording of that interaction as an elicitation tool. Video elicitation is useful because it allows researchers to integrate data about the content of physician-patient interactions gained from video recordings with data about participants' associated thoughts, beliefs, and emotions gained from elicitation interviews. This method also facilitates investigation of specific events or moments during interactions. Video elicitation interviews are logistically demanding and time consuming, and they should be reserved for research questions that cannot be fully addressed using either standard interviews or video recordings in isolation. As many components of primary care fall into this category, highquality video elicitation interviews can be an important method for understanding and improving physician-patient interactions in primary care.
\end{abstract}

Ann Fam Med 2012;10:118-125. doi:10.1370/afm.1339.

\section{INTRODUCTION}

$\mathrm{F}$ ace-to-face interactions between physicians and patients are central to primary care and an important focus of primary care research. Video elicitation interviews are one qualitative method for evaluating these interactions. Elicitation interviews use a stimulus, such as photographs ${ }^{1,2}$ or written records, ${ }^{3}$ to prompt participants to discuss subjects in greater detail than they would during standard interviews. During video elicitation interviews, researchers interview patients or physicians about a recent clinical interaction using a video recording of that interaction as an elicitation tool.

This article provides practical guidance for primary care researchers conducting video elicitation interviews. First, we briefly review existing social science and health care literature on this method. Next, we discuss the key steps for designing and conducting video elicitation interviews and make recommendations to researchers based on our experience conducting a video elicitation study of preventive services in primary care. ${ }^{4}$ Finally, we discuss the limitations of this method.

We focus on video elicitation interviews as a qualitative method for investigating physician-patient interactions. Researchers also conduct video elicitation interviews as interventions ${ }^{5,6}$ and for teaching purposes. ${ }^{7-9}$ These important applications have many similarities with video elicitation interviews used as research tools, but they have different primary goals and are not the focus of this article. We also focus on interactions involving real physicians and patients rather than studies of students interviewing actors, ${ }^{10,11}$ because the content and purpose of real and contrived interactions differ in important ways. ${ }^{12,13}$ 


\section{LITERATURE REVIEW}

The techniques used in video elicitation interviews were developed by researchers who studied counselor training, especially Norman Kagan ${ }^{14}$ and Frederick Erickson. ${ }^{15}$ To train counselors, Kagan developed a method called Interpersonal Process Recall in which an interviewer prompted trainees to comment and reflect on their video-recorded counseling sessions. Kagan found that trainees often failed to notice events or clients' reactions during counseling sessions. Trainees also frequently suppressed forthright discussions of the client's or their own fears and concerns because of perceived social pressure. A skilled interviewer could recognize these phenomena and prompt participants to notice overlooked events and admit their fears and concerns. ${ }^{14}$ These techniques are now common in the social sciences, especially in education (where they are often labeled stimulated recall). ${ }^{16-19}$ Variations of video elicitation interviews have been used in knowledge engineering, ${ }^{20}$ interaction analysis, ${ }^{21}$ anthropology, ${ }^{22}$ and other social science disciplines. ${ }^{23}$

Data from published video elicitation interview studies suggest that interview participants have 3 distinguishable kinds of experiences. ${ }^{14,16,21}$ First, participants typically recall the thoughts, beliefs, and emotions they experienced during the interaction. Second, participants frequently reexperience or relive the interaction while watching themselves on video and may even display physiologic or emotional changes in response to the events in the video recording. ${ }^{24}$ Finally, participants often reflect on their thoughts and actions or those of their interaction partner.

We conducted a thorough review of published video elicitation studies involving physician-patient interactions. Identifying the studies was difficult, because no standard terminology exists for this method. Terms used include Integrated Methodology for Preserving and Analyzing Clinical Transactions (IMPACT), ${ }^{25,26}$ stimulated recall, ${ }^{27}$ and video re-view. ${ }^{28}$ We adopted the term video elicitation from the nonmedical literature ${ }^{22}$ because it is more descriptive of the general method and highlights the methodological continuity with other elicitation techniques. We searched several electronic databases (PubMed, ISI Web of Knowledge, PsycINFO, Anthropology Plus, EMBASE, and ERIC) using the terms video elicitation,

\section{Table 1. Published Video Elicitation Interview Studies of Physician-patient Interactions}

\begin{tabular}{|c|c|c|c|}
\hline Author, Year & Topic & Participants & Comments on Study Methodology \\
\hline $\begin{array}{l}\text { Henry et al, }{ }^{4} \\
2011\end{array}$ & $\begin{array}{l}\text { Preventive services in primary } \\
\text { care }\end{array}$ & $\begin{array}{l}\text { Physicians } \\
\text { and patients }\end{array}$ & Secondary analysis of video elicitation interviews \\
\hline $\begin{array}{l}\text { Gao et al, }{ }^{27} \\
2009\end{array}$ & $\begin{array}{l}\text { Cross-cultural discussions of } \\
\text { colorectal cancer screening }\end{array}$ & Patients ${ }^{a}$ & Used experienced translators and bilingual interviewers \\
\hline $\begin{array}{l}\text { O'Brien et al, }{ }^{29} \\
2008\end{array}$ & $\begin{array}{l}\text { Decisions about breast cancer } \\
\text { treatment }\end{array}$ & Patients & Included interactions with both medical and surgical oncologists \\
\hline $\begin{array}{l}\text { Saba et al, } \\
2006\end{array}$ & $\begin{array}{l}\text { Shared decision making in } \\
\text { primary care }\end{array}$ & $\begin{array}{l}\text { Physicians } \\
\text { and patients }\end{array}$ & $\begin{array}{l}\text { Compared analysis of video recordings with analysis of video elicita- } \\
\text { tion interviews }\end{array}$ \\
\hline $\begin{array}{l}\text { Frankel et al, }{ }^{26} \\
2005\end{array}$ & $\begin{array}{l}\text { Instances of effective or } \\
\text { significant communication } \\
\text { during interactions }\end{array}$ & $\begin{array}{l}\text { Physicians } \\
\text { and patients }\end{array}$ & $\begin{array}{l}\text { Edited audio-recorded interview comments directly onto video } \\
\text { recordings before analysis; used both dyad and physician as units } \\
\text { of analysis }\end{array}$ \\
\hline $\begin{array}{l}\text { Fossum et al, }{ }^{31-33} \\
2004\end{array}$ & $\begin{array}{l}\text { Perceptions of communica- } \\
\text { tion and quality of care in } \\
\text { orthopedic clinics }\end{array}$ & $\begin{array}{l}\text { Physicians } \\
\text { and patients }\end{array}$ & $\begin{array}{l}\text { Examined associations among interaction sequence, content, and } \\
\text { patients' expressions of satisfaction during interviews }\end{array}$ \\
\hline $\begin{array}{l}\text { Coleman et } \text { al, }^{34-36} \\
1999\end{array}$ & $\begin{array}{l}\text { Discussions about smoking in } \\
\text { primary care }\end{array}$ & Physicians & $\begin{array}{l}\text { Investigator recorded several interactions with each physician and } \\
\text { chose } 1 \text { per physician for elicitation interviews. Participants watched } \\
\text { videos immediately before rather than during the interview }\end{array}$ \\
\hline $\begin{array}{l}\text { Epstein et al, }{ }^{37} \\
1998\end{array}$ & $\begin{array}{l}\text { HIV risk assessment in pri- } \\
\text { mary care }\end{array}$ & $\begin{array}{l}\text { Physicians } \\
\text { and patients }\end{array}$ & $\begin{array}{l}\text { Participants watched videos and made both spontaneous and HIV- } \\
\text { related comments. Video elicitation interviews were followed by } \\
\text { standard interviews focused on barriers to discussions of HIV risk }\end{array}$ \\
\hline $\begin{array}{l}\text { Cromarty, }^{38} \\
1996\end{array}$ & $\begin{array}{l}\text { Patients' thoughts during pri- } \\
\text { mary care interactions }\end{array}$ & Patients & $\begin{array}{l}\text { Interviewed a subset of participants from a larger sample of recorded } \\
\text { interactions; interviewed patients in their homes }\end{array}$ \\
\hline $\begin{array}{l}\text { Cegala et al, } \\
1996\end{array}$ & $\begin{array}{l}\text { Perceptions of communication } \\
\text { competence in primary care }\end{array}$ & $\begin{array}{l}\text { Physicians } \\
\text { and patients }\end{array}$ & $\begin{array}{l}\text { Used coded interviews for quantitative analysis; all interactions were } \\
\text { recorded in the same room using a wall-mounted camera }\end{array}$ \\
\hline $\begin{array}{l}\text { Arborelius, }{ }^{28,41-45} \\
\quad 1990\end{array}$ & $\begin{array}{l}\text { Comparison of physician and } \\
\text { patient perspectives; dilem- } \\
\text { mas in primary care }\end{array}$ & $\begin{array}{l}\text { Physicians } \\
\text { and patients }\end{array}$ & $\begin{array}{l}\text { Conducted } 2 \text { video elicitation interviews: } 1 \text { for spontaneous comments, } \\
\text { and } 1 \text { focused on content related to specific research questions }\end{array}$ \\
\hline $\begin{array}{l}\text { Treichler et al, } \\
\quad 1987\end{array}$ & $\begin{array}{l}\text { Power dynamics in physician- } \\
\text { patient interactions }\end{array}$ & $\begin{array}{l}\text { Physician } \\
\text { and patient }\end{array}$ & $\begin{array}{l}\text { Detailed, microanalysis of a single interaction; compares a physician's } \\
\text { and student's interaction with the same patient }\end{array}$ \\
\hline $\begin{array}{l}\text { Frankel et al, }{ }^{25} \\
\quad 1982\end{array}$ & $\begin{array}{l}\text { Comparison of physician and } \\
\text { patient perspectives }\end{array}$ & $\begin{array}{l}\text { Physicians } \\
\text { and patients }\end{array}$ & $\begin{array}{l}\text { Edited audio-recorded interview comments directly onto video record- } \\
\text { ings before analysis }\end{array}$ \\
\hline \multicolumn{4}{|c|}{ HIV = human immunodeficiency virus. } \\
\hline \multicolumn{4}{|c|}{ Note: Multiple articles analyzing the same set of video elicitation interviews are listed together in a single row. } \\
\hline \multicolumn{4}{|c|}{ a Study reports that physicians were interviewed, but only data from patient interviews were reported. } \\
\hline
\end{tabular}


stimulated recall, and interpersonal recall. We also manually searched references from published video elicitation interview studies. Table 1 summarizes our results.

Frankel and Beckman published the first video elicitation interview study of physician-patient interactions. ${ }^{25}$ They discovered that physicians and patients typically paused videos at the exact same moments when asked to identify moments that were new, unusual, or different. Many subsequent video elicitation studies have also compared physicians' and patients' perspectives.

The following sections discuss key steps for designing and conducting video elicitation interviews. Table 2 lists these steps and gives details of how we approached each step in our study. Few researchers have used this method to study physician-patient interactions. The variation in quality among studies in Table 1 reflects early experience with the method and the associated lack of well-defined procedures for its use in the health sciences. There is no single correct way to conduct video elicitation interviews, but our recommendations should provide valuable guidance for researchers conducting video elicitation interview studies of faceto-face interactions in health care. We hope the framework presented in this article will enable more primary care researchers to use this challenging but powerful method for investigating physician-patient interactions.

\section{CONCEPTUALIZING A VIDEO ELICITATION INTERVIEW STUDY}

Video elicitation interviews can produce high-quality data, but they are also more time consuming and complicated than standard qualitative methods. In our study,

\section{Table 2. Key Steps for Designing and Conducting Video Elicitation Interviews}

Step

Conceptualizing a video elicitation study

1. Choose a research question for which the added value of video elicitation interviews justifies the time and resources required

2. Decide on the scope of data collection

\section{Participants and sampling}

3. Determine the unit of analysis and sampling frame

4. Establish sufficient trust to record physicians

Data collection and management

5. Choose an appropriate video camera

6. Establish a protocol for recording interactions

7. Minimize the elapsed time between video recording and elicitation interviews

8. Determine the elicitation interview structure

9. Train interviewers

10. Determine a protocol for storing video recordings

11. Choose a transcription protocol for interviews

Data analysis

12. Review interview and data quality regularly

13. Decide how to integrate data from video recordings and elicitation interviews

14. Choose a method for analyzing elicitation interview data

Mitigating limitations of video elicitation interviews

15. Consider what kinds of interview data (recall, reliving, and/or reflection) are needed

16. Consider how social pressures related to interview setting may influence interview data
Example From Authors' Study

How do physicians' and patients' prioritize discussions of preventive services in primary care?

Interviewed participants about the entire interaction; asked participants to make unsolicited comments and respond to questions about preventive services delivery

Interviewed both physicians and patients; used convenience and snowball sampling; recruited physicians before patients; recruited patients ( 2 per physician) from waiting rooms; paid patients

Recruited physicians from investigator's local department and community; presented study aims to clinic staff using an academic detailing approach; offered individualized feedback sessions to physicians and clinics

Used a professional-grade, portable video camera with a fixed lens; used an adapted medical equipment stand (tripods would not fit in examination rooms)

Used checklists for equipment setup; frequently reviewed recordings to evaluate quality; obtained backup audio recordings; research assistant set up equipment on site and was not in room during the interaction; physicians covered lens during physical examination

Interviewed patients immediately after the interaction in available clinic space; used a laptop computer to play videos; interviewed physicians 1 to 2 weeks later as their schedules allowed

Conducted semistructured interviews; investigated both spontaneous comments and discussions about preventive services; interviewers and participants were encouraged to pause recordings and comment; variation among interactions made structured interviews difficult Investigator trained interviewers

Converted digital cassettes to computer files and stored them on secure servers; archived video recordings for future use

Used a standard protocol designed for studying medical discourse ${ }^{47}$

Discussed data and findings in regular debriefing meetings using transcripts; investigators participated in some interviews

Tried integrating transcripts from video recordings and interviews into a single document (which added considerable time and little additional insight); did not record exact times that participants' paused videos

Developed a theory-driven coding system for assessing statements likely to represent tacit clues

Did not address

Noted that patients often emphasized features they liked about their physicians; were alert to participant responses during interviews that reflected social desirability 
recording 36 interactions and conducting 72 video elicitation interviews took 13 months. Individual video elicitation interviews can last more than 2 hours each. ${ }^{29,38}$ Researchers should thus undertake video elicitation interviews only when simpler methods are inadequate. Table 3 lists the types of research questions for which video elicitation interviews are particularly useful, and gives examples drawn from the studies in Table 1.

The categories in Table 3 reveal several common themes. Video elicitation interviews are most useful for investigating social or interactional components of physician-patient interactions that cannot be adequately understood by either direct observation (eg, video recordings) or interviews alone. Cognitively complex or highly context-dependent aspects of primary care visits fall into this category. For example, understanding how patients' define effective communication requires evaluating both how physicians and patients communicate and how patients interpret

\section{Table 3. Types of Research Questions for Which Video Elicitation Interviews Are Useful}

\begin{tabular}{|c|c|}
\hline $\begin{array}{l}\text { Type of Research } \\
\text { Question }\end{array}$ & Examples From Published Video Elicitation Studies \\
\hline \multirow{3}{*}{$\begin{array}{l}\text { Complex cognitive } \\
\text { or decision-making } \\
\text { processes }\end{array}$} & $\begin{array}{l}\text { How often do physicians and patients identify nonverbal behaviors } \\
\text { or gestalt assessments that influence their judgments? }\end{array}$ \\
\hline & $\begin{array}{l}\text { How do patients' cultural norms and expectations influence discus- } \\
\text { sions about colorectal cancer screening? }{ }^{27}\end{array}$ \\
\hline & $\begin{array}{l}\text { What factors influence physicians' decisions to discuss smoking cessa- } \\
\text { tion with patients? }\end{array}$ \\
\hline \multirow{4}{*}{$\begin{array}{l}\text { Misunderstanding or } \\
\text { disagreement dur- } \\
\text { ing interactions }\end{array}$} & $\begin{array}{l}\text { How often do physicians and patients identify the same moments of } \\
\text { an interaction as "unusual" or "interesting"? }\end{array}$ \\
\hline & $\begin{array}{l}\text { How do physicians' and patients' perspectives on communication } \\
\text { competence differ? }{ }^{39}\end{array}$ \\
\hline & $\begin{array}{l}\text { How do physicians and patients' thoughts and feelings about infor- } \\
\text { mation exchange and relational communication differ? }{ }^{40}\end{array}$ \\
\hline & $\begin{array}{l}\text { What kinds of dilemmas do general practitioners experience during } \\
\text { physician-patient interactions? }\end{array}$ \\
\hline \multirow[t]{2}{*}{$\begin{array}{l}\text { Sensitive, emotional, } \\
\text { or stigmatized topics }\end{array}$} & $\begin{array}{l}\text { What factors are associated with effective discussions of HIV risk dur- } \\
\text { ing primary care interactions? }\end{array}$ \\
\hline & $\begin{array}{l}\text { What power dynamics exist between physicians, patients, and medi- } \\
\text { cal students? }\end{array}$ \\
\hline \multirow{3}{*}{$\begin{array}{l}\text { Defining effective } \\
\text { communication and } \\
\text { management for } \\
\text { complex problems }\end{array}$} & $\begin{array}{l}\text { What processes and stages of treatment decision making are per- } \\
\text { ceived by women with early stage breast cancer }{ }^{29}\end{array}$ \\
\hline & $\begin{array}{l}\text { How do communication behaviors associated with shared decision } \\
\text { making relate to patients' and physicians' subjective experience of } \\
\text { partnership? }\end{array}$ \\
\hline & $\begin{array}{l}\text { How do orthopedic surgeons manage interactions, and how do these } \\
\text { management strategies relate to patient satisfaction? } \text { ? }^{32}\end{array}$ \\
\hline \multirow{2}{*}{$\begin{array}{l}\text { Influences on partici- } \\
\text { pants' impressions } \\
\text { and behaviors after } \\
\text { interactions }\end{array}$} & $\begin{array}{l}\text { How do comments from physicians with high patient satisfaction } \\
\text { scores compare with comments from physicians with low patient } \\
\text { satisfaction scores? }\end{array}$ \\
\hline & How do patients define "good" vs "bad" physicians?44 \\
\hline \multirow{4}{*}{$\begin{array}{l}\text { Participants' reactions } \\
\text { to or assessments of } \\
\text { their own actions }\end{array}$} & How do orthopedic surgeons experience interactions with patients? ${ }^{31}$ \\
\hline & How do patients experience interactions with orthopedic surgeons? ${ }^{33}$ \\
\hline & What thoughts do patients have during primary care interactions? ${ }^{38}$ \\
\hline & $\begin{array}{l}\text { How do general practitioners experience and understand physician- } \\
\text { patient interactions? }\end{array}$ \\
\hline
\end{tabular}

and evaluate physicians' actions. ${ }^{39}$ On the other hand, video elicitation interviews would probably not be necessary to describe time use during primary care visits.

Video elicitation interviews also facilitate investigation of specific events during interactions and fluctuations in participants' thoughts and feelings within a single interaction. A person's memory and insight into his or her own mental processes are notoriously imperfect and inaccurate. ${ }^{48-51}$ Video elicitation interviews can facilitate more accurate recall of specific events that participants are likely to forget or misremember during standard interviews. Participants often notice new or unexpected aspects of the interaction during video elicitation interviews. ${ }^{34,37,41}$

This method generates large amounts of data, so researchers should consider the scope of data collection. Considerable time and money might be saved by interviewing participants about only those segments of the video recording that are relevant to the research question. An overly narrow focus, however, might miss important contextual information by relying on researchers (rather than participants) to identify segments of interest. A narrow focus also limits the potential for secondary analysis.

\section{PARTICIPANTS AND SAMPLING}

Researchers should decide whether they need to interview physicians, patients, or both for their study. The cost of video elicitation interviews typically limits sample size, so purposeful sampling across characteristics of interest may be more efficient than random or convenience sampling.

Patients and health care workers generally support the idea of recording physician-patient interactions, ${ }^{52}$ but physicians may be difficult to recruit because they worry that being video recorded will disrupt workflow or create liability concerns. ${ }^{53}$ Obtaining buy-in from physicians and clinic staff is critically important. Investigators should participate in recruiting physicians and clinics whenever possible. Additional 
strategies to address physicians' concerns include conducting preliminary field work, ${ }^{5}$ obtaining certificates of confidentiality, ${ }^{54}$ and offering to share study results. We found that patients were typically less worried than physicians about being recorded and were often eager to participate.

Even though researchers and physicians worry that being recorded will influence participants' behavior, ${ }^{52}$ researchers investigating camera-related behaviors in different clinical settings have found scant evidence to suggest that video recording changes participant behavior. ${ }^{53,55-58}$ Findings from video elicitation interview studies, including ours, support this conclusion. ${ }^{42,59}$ Once physicians are engaged with a patient, they fall into clinical routines that are difficult to change much even with conscious effort. Selection bias among participants who consent to video-recording may be a more important concern. ${ }^{35,53,59}$

\section{DATA COLLECTION AND MANAGEMENT}

High-quality video recordings are necessary for video elicitation interviews; audio recordings cannot capture the full range of verbal and nonverbal communication during physician-patient interactions ${ }^{60,61}$ and are unlikely to stimulate participant recall during interviews. Physicians and patients should be recorded in a single video frame. We used a professional-quality camera that recorded onto digital cassettes and constructed a portable camera stand that could fit easily into examination rooms (see the Supplemental Figure

at http://annfammed.org/content/10/2/118/suppl/

H. DC1). Researchers can buy high-quality portable cameras that can record directly onto hard drives or other storage devices for less than $\$ 1,000$. Ceilingmounted cameras may be appropriate for researchers planning to record multiple interactions in the same room. The camera lens should have a wide-angle capacity sufficient for the setting. Having study personnel adjust camera angles during interactions is both impractical and distracting, so portable cameras must be positioned in rooms at the start of each interaction. Researchers should standardize camera operation protocols and use backup audio recorders to minimize data loss from equipment malfunction.

Video elicitation interviews should be conducted as soon as possible after interactions so that participants' memories will be fresh. We interviewed patients immediately after video recording, but we typically interviewed physicians 1 to 2 weeks later to accommodate clinic schedules. This delay may partially account for our finding that physicians were more likely than patients to discuss preventive services in general, abstract terms. We employed 2 study personnel per interview (1 to interview and another to operate equipment and take notes), though it may be feasible to conduct video elicitation interviews with one interviewer if the interviewer is experienced and well-trained. Conducting a video recording and 2 separate video elicitation interviews on the same day may be difficult. Researchers should prioritize the timing of recruitment, video recording, and interviews based on local conditions and resources, and should report the time elapsed between recordings and interviews in published studies.

Interview structure strongly influences the kinds of data collected during video elicitation interviews. Researchers should design interviews based on the kinds of data they want (ie, recall, reliving, or reflection) and their research focus (ie, broad vs specific). In our study, we reminded participants of the study purpose and encouraged them to pause the video and comment during discussions of preventive services. Interviewers also incorporated open-ended questions about preventive services into the interview. The full interview guide is available online in the Supplemental Appendix at http://annfammed.org/content/10/2/118/suppl/ DC1. Interviewers were advised to pause the video when preventive services were discussed if participants did not. For taciturn participants, interviewers paused the video approximately every 5 minutes and asked participants to comment on their thoughts and feelings. In our study, physicians and most patients required minimal prompting to talk at length about the video recording.

Interviewer skill is arguably the most important component of video elicitation interviews and can make the difference between high-quality and mediocre data. In addition to standard interviewing skills, interviewers must be able to keep participants focused on the specific moments or events they observe on the video recording. This practice maximizes the benefit of video elicitation interviews. Table 4 displays examples of questions that interviewers can use to keep participants focused on the interaction. Physicians in our study tended to discuss preventive services in general terms, which resulted in a challenge for interviewers. Ideally, interviewers should thoroughly understand the research question(s), be able to recognize and prompt participants to provide the kinds of data desired (ie, recall, reliving, or reflection), and be able to recognize unanticipated comments that are potentially relevant to the study.

Researchers will rarely have access to interviewers with this level of skill, so adequate training before data collection is critical. In our study researchers met and trained interviewers and assessed interview quality using written transcripts. Based on our experience, however, interviewers need intensive hands-on experience and training to become proficient. We rec- 


\begin{tabular}{|c|c|}
\hline $\begin{array}{l}\text { Question } \\
\text { Goal }\end{array}$ & Sample Question \\
\hline $\begin{array}{l}\text { Thoughts, } \\
\text { beliefs, and } \\
\text { emotions }\end{array}$ & $\begin{array}{l}\text { What were you doing/trying to do at this point in the visit? } \\
\text { What were you noticing/hearing at this point? } \\
\text { Were there any other thoughts going through your mind? } \\
\text { Can you tell me what you felt at this point? } \\
\text { Can you recall more details about your feelings? } \\
\text { What makes this moment in particular stand out to you? } \\
\text { How did you want the other person to perceive you? } \\
\text { Why did you make that statement/ask that question? }\end{array}$ \\
\hline $\begin{array}{l}\text { Impressions } \\
\text { of others }\end{array}$ & $\begin{array}{l}\text { What did you think the physician/patient was thinking } \\
\text { about you at this point? } \\
\text { What were your impressions of the physician's/patient's } \\
\text { actions at this point? } \\
\text { Why do you think the physician/patient made that state- } \\
\text { ment at this moment? }\end{array}$ \\
\hline $\begin{array}{l}\text { Impressions } \\
\text { of self }\end{array}$ & $\begin{array}{l}\text { What do you notice about your actions at this point? } \\
\text { What about your behavior at this point surprises you? }\end{array}$ \\
\hline $\begin{array}{l}\text { Decision } \\
\text { making } \\
\text { processes }\end{array}$ & $\begin{array}{l}\text { What let you know that was the right decision to make at } \\
\text { this point? } \\
\text { What information did you use in making this decision? } \\
\text { What other courses of action were you considering or were } \\
\text { available to you? } \\
\text { What made you decide this was the right decision at this } \\
\text { point in time? } \\
\text { How much time pressure did you feel in making this decision? } \\
\text { If the patient had said X instead of Y, how would that have } \\
\text { influenced your decisions and/or assessment? }\end{array}$ \\
\hline
\end{tabular}

and should be archived to allow for potential secondary analyses. When applicable, initial participant consent should include permission for the use of videos in education, scientific presentations, and secondary analyses.

\section{DATA ANALYSIS}

Researchers should select methods for analyzing video and audio recordings based on their specific research question(s). Most published video elicitation interview studies focus on written interview transcripts. Systematic analysis of nonverbal communication requires more time and a substantively higher skill level. Detailed descriptions of qualitative methods for analyzing audio recordings, video recordings, and transcripts have been published elsewhere ${ }^{63,64}$ and are beyond the scope of this article. One important consideration, however, is how to integrate data from video recordings and elicitation interviews. Interviewers should record the exact times that participants pause videos, so that researchers can accurately reconstruct the timing of comments relative to events on the video recording. We initially integrated audio and video transcripts into a single document; this process was time consuming without detailed records of when participants paused the video recordings. We therefore discontinued this process once we determined that the exact timing of participants' comments added little to our analysis. When the precise temporal relationships between video recordings and interview comments are important for analysis, video editing software can be used to splice together the audio and video recordings before transcription and data analysis. ${ }^{26,37}$ For research questions that do not focus on specific events during interactions, video recordings and interview data can be analyzed separately and then compared. ${ }^{30}$

\section{MITIGATING LIMITATIONS OF VIDEO ELICITATION INTERVIEWS}

Primary care researchers should be aware of several limitations of video elicitations that have been identified by social scientists. ${ }^{14,16,21,23}$ Researchers may have difficulty distinguishing whether comments during video elicitation interviews represent recollection, reliving, or reflection. ${ }^{21}$ By extension, participants' comments during an interview do not always reflect their actual thoughts, beliefs, or emotions during that interaction. Instead, participants may reconstruct or misremember their thoughts, beliefs, or emotions based 
on the video recording rather than on their actual recollection or experience. Researchers can minimize this possibility by carefully designing interview instructions and by paying attention to how participants' comments relate to video-recorded events during the interview. ${ }^{16}$

In addition, much as social and interactional pressures during physician-patient interactions often cause participants to behave diplomatically, ${ }_{1}^{14}$ social and interactional pressures also exist during the interview itself. Participants' comments may be oriented to the context of the research interview rather than to the events in the video recording ${ }^{65}$; accordingly, even high-quality video elicitation interview data are not immune to bias. In addition, limitations related to humans' imperfect memory and poor insight into mental processes are common to all self-report data. To our knowledge no one has directly compared video elicitation interviews with standard interviews. Social scientists and primary care researchers who have used the method, however, argue convincingly that high-quality video elicitation interviews generate more detailed and more accurate data than do standard interviews. $16,18,21,25,42$

Only a few studies in Table 1 discuss or even indicate awareness of the different types of data (ie, recall, reliving, and reflection) video elicitation interviews can produce. Nor do study authors discuss the potential for subtle bias resulting from the interview setting or misremembering. Primary care researchers can improve data quality by designing their study to focus on the kinds of data they want, and by training interviewers to be alert for the sources of bias most relevant to the study. Researchers should publish details about their interview processes and instructions to participants so that readers can assess data quality and potential bias.

To read or post commentaries in response to this article, see it online at http://www.annfammed.org/content/10/2/118.

Key words: video elicitation interviews; video recording; qualitative research; physician-patient relations; stimulated recall; interpersonal recall

Submitted February 14, 2011; submitted, revised, August 12, 2011; accepted August 30, 2011.

Funding support: This project was funded by a grant from the Robert Wood Johnson Foundation Generalist Faculty Scholars program (Dr Fetters). Dr Henry is supported by the us Department of Veterans Affairs and the Robert Wood Johnson Foundation Clinical Scholars program.

\section{References}

1. Frith H, Harcourt D. Using photographs to capture women's experiences of chemotherapy: reflecting on the method. Qual Health Res. 2007;17(10):1340-1350.

2. Baker TA, Wang CC. Photovoice: use of a participatory action research method to explore the chronic pain experience in older adults. Qual Health Res. 2006;16(10):1405-1413.
3. Guerra CE, Schwartz JS, Armstrong K, Brown JS, Halbert CH, Shea JA. Barriers of and facilitators to physician recommendation of colorectal cancer screening. J Gen Intern Med. 2007;22(12):1681-1688.

4. Henry SG, Forman JH, Fetters MD. 'How do you know what Aunt Martha looks like?' A video elicitation study exploring tacit clues in doctor-patient interactions. J Eval Clin Pract. 2011; 17(5):933-939.

5. Carroll K, ledema R, Kerridge R. Reshaping ICU ward round practices using video-reflexive ethnography. Qual Health Res. 2008; 18(3):380-390.

6. Harms C, Young JR, Amsler F, Zettler C, Scheidegger D, Kindler CH. Improving anaesthetists' communication skills. Anaesthesia. 2004; 59(2):166-172.

7. Chou C, Lee K. Improving residents' interviewing skills by group videotape review. Acad Med. 2002;77(7):744.

8. Beckman HB, Frankel RM. The use of videotape in internal medicine training. J Gen Intern Med. 1994;9(9):517-521.

9. Neufeld VR, Norman GR, Feightner JW, Barrows HS. Clinical problem-solving by medical students: a cross-sectional and longitudinal analysis. Med Educ. 1981;15(5):315-322.

10. Shelley BM, Sussman AL, Williams RL, Segal AR, Crabtree BF; Rios Net Clinicians. 'They don't ask me so I don't tell them': patientclinician communication about traditional, complementary, and alternative medicine. Ann Fam Med. 2009;7(2):139-147.

11. Hulsman RL, Harmsen AB, Fabriek M. Reflective teaching of medical communication skills with DiViDU: assessing the level of student reflection on recorded consultations with simulated patients. Patient Educ Couns. 2009;74(2):142-149.

12. Ram P, van der Vleuten C, Rethans JJ, Grol R, Aretz K. Assessment of practicing family physicians: comparison of observation in a multiple-station examination using standardized patients with observation of consultations in daily practice. Acad Med. 1999;74(1):62-69.

13. Henry SG. A piece of my mind. Playing doctor. JAMA. 2005;294(17): 2138-2140.

14. Kagan N. Influencing human interaction-eighteen years with IPR. In: Hess AK, ed. Psychotherapy Supervision: Theory, Research, and Practice. New York, NY: John Wiley \& Sons; 1980:262-283.

15. Erickson F, Shultz JJ. The Counselor as Gatekeeper: Social Interaction in Interviews. New York, NY: Academic Press; 1982.

16. Lyle J. Stimulated recall: A report on its use in naturalistic research. Br Educ Res J. 2003;29(6):861-878.

17. Gass SM, Mackey A. Stimulated Recall Methodology in Second Language Research. Mahwah, NJ: L. Erlbaum Associates; 2000.

18. Vesterinen $\mathrm{O}$, Toom $\mathrm{A}$, Patrikainen $\mathrm{S}$. The stimulated recall method and ICTs in research on the reasoning of teachers. Int J Res Method Educ. 2010;33(2):183-197.

19. Sewall M. Transforming supervision: using video elicitation to support preservice teacher-directed reflective conversations. Issues Teach Educ. 2009;18(2):11-30.

20. Crandall B, Klein GA, Hoffman RR. Working minds: A Practitioner's Guide to Cognitive Task Analysis. Cambridge, MA: MIT Press; 2006.

21. Pomerantz A. Using participants' video stimulated comments to complement analyses of interactional practices. In: te Molder $\mathrm{H}$, Potter J, eds. Talk and Cognition: Discourse, Mind, and Social Interaction. Cambridge, MA: Cambridge University Press; 2005:93-113.

22. Nastasi BK. Audiovisual methods in ethnography. In: Schensul JJ, LeCompte MD, Nastasi BK, Borgatti SP, eds. Enhanced Ethnographic Methods: Audiovisual Techniques, Focused Group Interviews, and Elicitation Techniques. Thousand Oaks, CA: Altamira Press; 1999:1-50.

23. Rosenstein $B$. Video use in social science research and program evaluation. Intl J Qual Methods. 2002;1(3):22-43.

24. Gottman JM, Levenson RW. A valid procedure for obtaining selfreport of affect in marital interaction. J Consult Clin Psychol. 1985; 53(2):151-160 
25. Frankel RM, Beckman HB. IMPACT: An interaction-based method for preserving and analysing clinical transactions. In: Pettigrew LS, ed. Straight Talk: Explorations in Provider and Patient Interactions. Louisville, KY: Humana, Inc; 1982:71-85.

26. Frankel RM, Sung SH, Hsu JT. Patients, doctors, and videotape: a prescription for creating optimal healing environments? J Altern Complement Med. 2005;11(Suppl 1):S31-S39.

27. Gao G, Burke N, Somkin CP, Pasick R. Considering culture in physician-patient communication during colorectal cancer screening. Qual Health Res. 2009;19(6):778-789.

28. Arborelius E, Timpka T. Comparison of patients' and doctors' comments on video-recorded consultations. Scand J Prim Health Care. 1991;9(2):71-77.

29. O'Brien MA, Whelan TJ, Charles C, et al. Women's perceptions of their treatment decision-making about breast cancer treatment. Patient Educ Couns. 2008;73:431-436.

30. Saba GW, Wong ST, Schillinger D, et al. Shared decision making and the experience of partnership in primary care. Ann Fam Med. 2006;4(1):54-62.

31. Fossum B, Arborelius E, Theorell T. How physicians experience patient consultations at an orthopaedic out-patient clinic: a qualitative study. Patient Educ Couns. 2002;47(2):127-135.

32. Fossum B, Arborelius E. Patient-centred communication: videotaped consultations. Patient Educ Couns. 2004;54(2):163-169.

33. Fossum B, Arborelius E, Theorell T. How do patients experience consultations at an orthopaedic out-patient clinic? Eighteen patients comment on video-taped consultations: a qualitative study. Eur J Public Health. 1998;8(1):59-65.

34. Coleman T, Murphy E. Combining qualitative interviews with videorecorded consultations: gaining insight into GPs' decision-making. Fam Pract. 1999;16(2):173-178.

35. Coleman T, Manku-Scott T. Comparison of video-recorded consultations with those in which patients' consent is withheld. $\mathrm{Br} J \mathrm{Gen}$ Pract. 1998;48(427):971-974.

36. Coleman T, Murphy E, Cheater F. Factors influencing discussion of smoking between general practitioners and patients who smoke: a qualitative study. Br J Gen Pract. 2000;50(452):207-210.

37. Epstein RM, Morse DS, Frankel RM, Frarey L, Anderson K, Beckman HB. Awkward moments in patient-physician communication about HIV risk. Ann Intern Med. 1998;128(6):435-442.

38. Cromarty I. What do patients think about during their consultations? A qualitative study. Br J Gen Pract. 1996;46(410):525-528.

39. Cegala DJ, McGee DS, McNeilis KS. Components of patients' and doctors' perceptions of communication competence during a primary care medical interview. Health Commun. 1996;8(1):1-27.

40. Cegala DJ, Mcneilis KS, Mcgee DS, Jonas AP. A study of doctors and patients perceptions of information processing and communication competence during the medical interview. Health Commun. 1995;7(3):179-203.

41. Timpka T, Arborelius E. A method for study of dilemmas during health care consultations. Med Inform (Lond). 1991;16(1):55-64.

42. Arborelius E, Timpka T. In what way may videotapes be used to get significant information about the patient-physician relationship? Med Teach. 1990;12(2):197-208.

43. Arborelius E, Timpka T. General practitioners' comments on video recorded consultations as an aid to understanding the doctorpatient relationship. Fam Pract. 1990;7(2):84-90.

44. Arborelius E, Timpka T, Nyce JM. Patients comment on videorecorded consultations-the "good" GP and the "bad". Scand J Soc Med. 1992;20(4):213-216.

45. Timpka T, Arborelius E. The GP's dilemmas: a study of knowledge need and use during health care consultations. Methods Inf Med. $1990 ; 29(1): 23-29$
46. Treichler PA, Frankel RM, Kramarae C, Zoppi K, Beckman HB. Problems and problems: power relationships in a medical encounter. In: Mayor BM, Pugh AK, eds. Language, Communication, \& Education. Wolfeboro, NH; London: Croom Helm; Open University Press; 1987:62-88.

47. Waitzkin $\mathrm{H}$. On studying the discourse of medical encounters. A critique of quantitative and qualitative methods and a proposal for reasonable compromise. Med Care. 1990;28(6):473-488.

48. Smith D, Loewenstein $G$, Jepson $C$, Jankovich A, Feldman $H$, Ubel $P$. Mispredicting and misremembering: patients with renal failure overestimate improvements in quality of life after a kidney transplant. Health Psychol. 2008;27(5):653-658.

49. Hertwig R, Fanselow C, Hoffrage U. Hindsight bias: how knowledge and heuristics affect our reconstruction of the past. Memory. 2003;11(4-5):357-377.

50. Nisbett RE, Wilson TD. Telling more than we can know: Verbal reports on mental processes. Psychol Rev. 1977;84(3):231-259.

51. Johansson $P$, Hall $L$, Sikström $S$, Tärning $B$, Lind $A$. How something can be said about telling more than we can know: on choice blindness and introspection. Conscious Cogn. 2006;15(4):673-692, discussion 693-699.

52. Rushmer R, Themessel-Huber M, Coyle J, Humphris G, Dowell J, Williams $B$. Is the routine recording of primary care consultations possible....and desirable? Lessons for researchers from a consultation with multiple stakeholders. Patient Educ Couns. 2011;82(2):247-253.

53. Themessl-Huber M, Humphris G, Dowell J, Macgillivray S, Rushmer $\mathrm{R}$, Williams B. Audio-visual recording of patient-GP consultations for research purposes: a literature review on recruiting rates and strategies. Patient Educ Couns. 2008;71(2):157-168.

54. Certificates of Confidentiality Kiosk. US Department of Health $\&$ Human Services; 2011. http://grants.nih.gov/grants/policy/coc/. Accessed Jan 11, 2011.

55. Pringle M, Stewart-Evans $C$. Does awareness of being video recorded affect doctors' consultation behaviour? Br J Gen Pract. 1990;40(340):455-458

56. Campbell LM, Howie JGR, Murray TS. Use of videotaped consultations in summative assessment of trainees in general practice. $\mathrm{Br} J$ Gen Pract. 1995;45(392):137-141

57. Penner LA, Orom H, Albrecht TL, Franks MM, Foster TS, Ruckdeschel JC. Camera-related behaviors during video recorded medical interactions. J Nonverbal Behav. 2007;31(2):99-117.

58. Zhou Y, Forbes GM, Humphris G. Camera-related behaviours of female dental nurses and nursery school children during fluoride varnish application interactions in nursery school settings. Int J Paediatr Dent. 2010;20(5):374-381.

59. Coleman T. Using video-recorded consultations for research in primary care: advantages and limitations. Fam Pract. 2000;17(5):422-427

60. Heath C. Body Movement and Speech in Medical Interaction. Ekman P, Scherer KR, eds. Cambridge, UK \& Paris: Cambridge University Press $\&$ Editions de la Maison des Sciences de I'Homme; 1986.

61. Mast MS. On the importance of nonverbal communication in the physician-patient interaction. Patient Educ Couns. 2007;67(3):315-318

62. Block MR, Schaffner KF, Coulehan JL. Ethical problems of recording physician-patient interactions in family practice settings. J Fam Pract. 1985;21(6):467-472.

63. Bourgeault IL, Dingwall R, DeVries RG. The SAGE Handbook of Qualitative Methods in Health Research. Los Angeles, CA: SAGE; 2010.

64. Heath $C$, Luff $P$, Svensson MS. Video and qualitative research: analysing medical practice and interaction. Med Educ. 2007;41(1):109-116.

65. Mills CW. Situated actions and vocabularies of motive. Am Socio Rev. 1940;5(6):904-913. 